\title{
Ustekinumab in Real-Life Practice: Experience in 116 Patients with Moderate-To-Severe Psoriasis
}

\author{
Ustekinumab no Tratamento de Psoríase Moderada a \\ Grave: Experiência em 116 Doentes da Prática Clínica
}

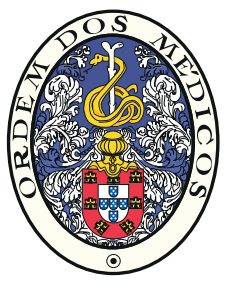
Inês RAPOSO ${ }^{1}$, Andreia BETTENCOURT², Luiz LEITE ${ }^{3}$, Manuela SELORES ${ }^{1,4,5}$, Tiago TORRES $\bigotimes^{1,4,5}$
Acta Med Port $\mathbf{2 0 1 9}$ Mar;32(3):214-218 - $\underline{\text { https://doi.org/10.20344/amp.10728 }}$

\section{ABSTRACT}

Introduction: Ustekinumab is a monoclonal antibody directed against the p40 subunit common to both IL-12 and IL-23 cytokines. Although the evidence of ustekinumab efficacy and safety in clinical trials is extensively recognized, data on its use in clinical practice is limited. Our objective is to report on the real-life experience of two Portuguese dermatology departments with ustekinumab in patients with moderate to severe psoriasis, and to identify the clinical characteristics associated with a weaker clinical response.

Material and Methods: Clinical, demographic, and therapeutic response data was retrospectively collected in 116 patients with moderate to severe psoriasis treated with ustekinumab between November 2009 and December 2015.

Results: A PASI75 therapeutic response was observed in $67.2 \%, 85.3 \%, 89.6 \%$ and $88.7 \%$ of patients at weeks $4,12,24$ and 52 , respectively. Ustekinumab was discontinued in seven patients (three due to primary failure, three due to secondary treatment failure, and one due to adverse events). Neither cardiovascular events nor cases of reactivation of previous infections (tuberculosis, hepatitis B) were observed during follow-up. In nine patients methotrexate was used as adjuvant therapy, and fourteen patients required ustekinumab dosage optimization. No side effects were observed in the two latter groups. The therapeutic response was higher in patients naïve to biologic therapies as compared to non-naïve patients.

Discussion and Conclusion: A trend towards lower clinical response was observed in patients weighing between 90-100 kg, and dosage optimization in this group of patients may be of value prior to considering biologic switch.

Keywords: Biological Products/therapeutic use; Psoriasis/drug therapy; Ustekinumab/therapeutic use

\section{RESUMO}

Introdução: O ustekinumab é um anticorpo monoclonal dirigido contra a subunidade p40 presente nas IL-12 e 23. A evidência da sua eficácia e segurança em ensaios clínicos é amplamente conhecida. No entanto a evidência da sua utilização na prática clínica é relativamente limitada na população Portuguesa. O objetivo deste trabalho é relatar a experiência de dois serviços de dermatologia Portugueses no tratamento da psoríase moderada a grave com ustekinumab.

Material e Métodos: Foram avaliados os dados clínicos, demográficos, e de resposta terapêutica ao ustekinumab em 116 doentes com psoríase tratados entre novembro de 2009 e dezembro de 2015.

Resultados: Observou-se uma resposta terapêutica $\geq$ PASI 75 em $67,2 \%, 85,3 \%, 89,6 \%$ e $88,7 \%$ dos doentes às semanas $4,12,24$ e 52, respetivamente. O ustekinumab foi descontinuado em sete doentes (três por falências primárias, três por falências secundárias e um por evento adverso). Não foram observados eventos cardiovasculares nem reativações de infecções prévias (tuberculose, hepatite B). Em nove doentes foi utilizado em simultâneo metotrexato, e em catorze foi necessário otimizar a dose de ustekinumab. Não foram observados efeitos colaterais nestes grupos. A resposta terapêutica foi superior nos doentes naïve a terapêuticas biológicas comparativamente com os doentes não-naïve. Observou-se uma tendência para resposta clínica inferior nos doentes com peso entre $90-100 \mathrm{~kg}$.

Discussão e Conclusão: Este estudo confirma a segurança e eficácia de ustekinumab no tratamento da psoríase moderada a grave em doentes da prática clínica real, sustenta a eficácia mesmo nos doentes previamente expostos a terapêutica biológica e aponta para a possível necessidade de ajustar a dose a partir dos $90 \mathrm{~kg}$.

Palavras-chave: Biológicos/uso terapêutico; Psoríase/tratamento; Ustekinumab/uso terapêutico

\section{INTRODUCTION}

Ustekinumab is a monoclonal antibody targeting the p40 subunit common to the IL-12 and 23 cytokines, ${ }^{1}$ whose therapeutic efficacy and safety are well documented in clinical trial populations..$^{2,3}$

Body weight affects clearance capacity and volume of distribution of numerous drugs. ${ }^{4}$ Specifically, in the case of ustekinumab, the patient's weight exerts a pronounced influence on pharmacokinetics by altering the drug clearance and distribution volume. ${ }^{5}$ This is the rationale for the recom- mendation of different dosing regimens of ustekinumab in patients below and above a defined weight threshold (45 mg or $90 \mathrm{mg}$ every 12 weeks in patients weighting $<100 \mathrm{~kg}$ and $\geq 100 \mathrm{~kg}$, respectively). ${ }^{4,6}$

As compared with clinical trials, the real-life practice with ustekinumab showed that a proportion of patients is either unresponsive or loses efficacy with the aforementioned dosing regimen..$^{6-9}$ This scenario often leads to ustekinumab dosage increase, interval adjustments, introduction of

1. Department of Dermatology. Centro Hospitalar do Porto. Porto. Portugal.

2. Immunogenetics laboratory. Instituto Ciências Biomédicas Abel Salazar. University of Porto. Porto. Portugal.

3. Clínica Laser de Belém. Lisboa. Portugal.

4. Instituto de Ciências Biomédicas Abel Salazar. University of Porto. Porto. Portugal.

5. Dermatology Research Unit. Centro Hospitalar do Porto. Porto. Portugal.

$\triangle$ Autor correspondente: Tiago Torres. torres.tiago@outlook.com

Recebido: 26 de abril de 2018 - Aceite: 26 de novembro de 2018 | Copyright @ Ordem dos Médicos 2019 
adjuvant therapy, or biologic switch. ${ }^{6,10-14}$ Additionally, previous experience in clinical trials and real-life practice showed that, in certain patient groups the loss of therapeutic response can be a transitory phenomenon, and the intensification of the drug regimen may allow the maintenance of the initial biologic, as such avoiding the 'exhaustion' of other therapeutic choices. ${ }^{15}$

Analysis of data derived from real-life practice that would enable the identification of clinical characteristics associated with a weaker clinical response, would, in some patients, allow considering alternative dosing regimens rather than just switching biologics.

The objective of our study is to identify the clinical characteristics associated with a weaker clinical response in patients with psoriasis treated with ustekinumab.

\section{MATERIAL AND METHODS}

The real-life experience of two Portuguese dermatology departments with ustekinumab in the treatment of moderate to severe psoriasis is hereby presented through a retrospective observational patient cohort. Clinical data of 116 patients treated with ustekinumab in Centro Hospitalar do Porto (Porto) and Clinica Laser de Belém (Lisboa) between November 2009 and December 2015 were collected. De- mographic data, history of psoriasis (age of onset, family history), presence of psoriatic arthritis (PsA), baseline Psoriasis Area Severity Index (PASI), along with previous therapies, comorbidities, serious adverse events (SAE), and therapeutic response were assessed.

\section{RESULTS}

\section{Cohort clinical and demographic characteristics}

A total of 116 patients with moderate-to-severe psoriasis (50 female and 66 male patients) treated with ustekinumab were retrospectively analysed. The mean age of onset of psoriasis in our cohort was 26 years ( \pm 15.2 , range $2-71$ ), while mean disease duration was 21.8 years $( \pm 12.8$, range 4 - 62). Twenty-four (20.7\%) patients had a diagnosis of PsA in our cohort. Regarding disease severity, the mean baseline PASI was 13.2 ( \pm 5.1 , range $8-27.6)$. Mean weight of our cohort of patients was $78.3 \mathrm{~kg}( \pm 17.2$, range $46-118)$, and mean body mass index (BMI) was 27.3 ( \pm 5.1 , range 17.9 - 46.9).

The prevalence of cardiovascular risk factors was analysed: hypertension was present in $30.2 \%$ patients, dyslipidaemia in $30.2 \%$, and diabetes in $11.2 \%$ patients. Obesity $(\mathrm{BMI}>30)$ and overweight (BMI $25-30)$ were identified in $23.3 \%$ and $39.7 \%$ of our patient cohort, respectively. Re-
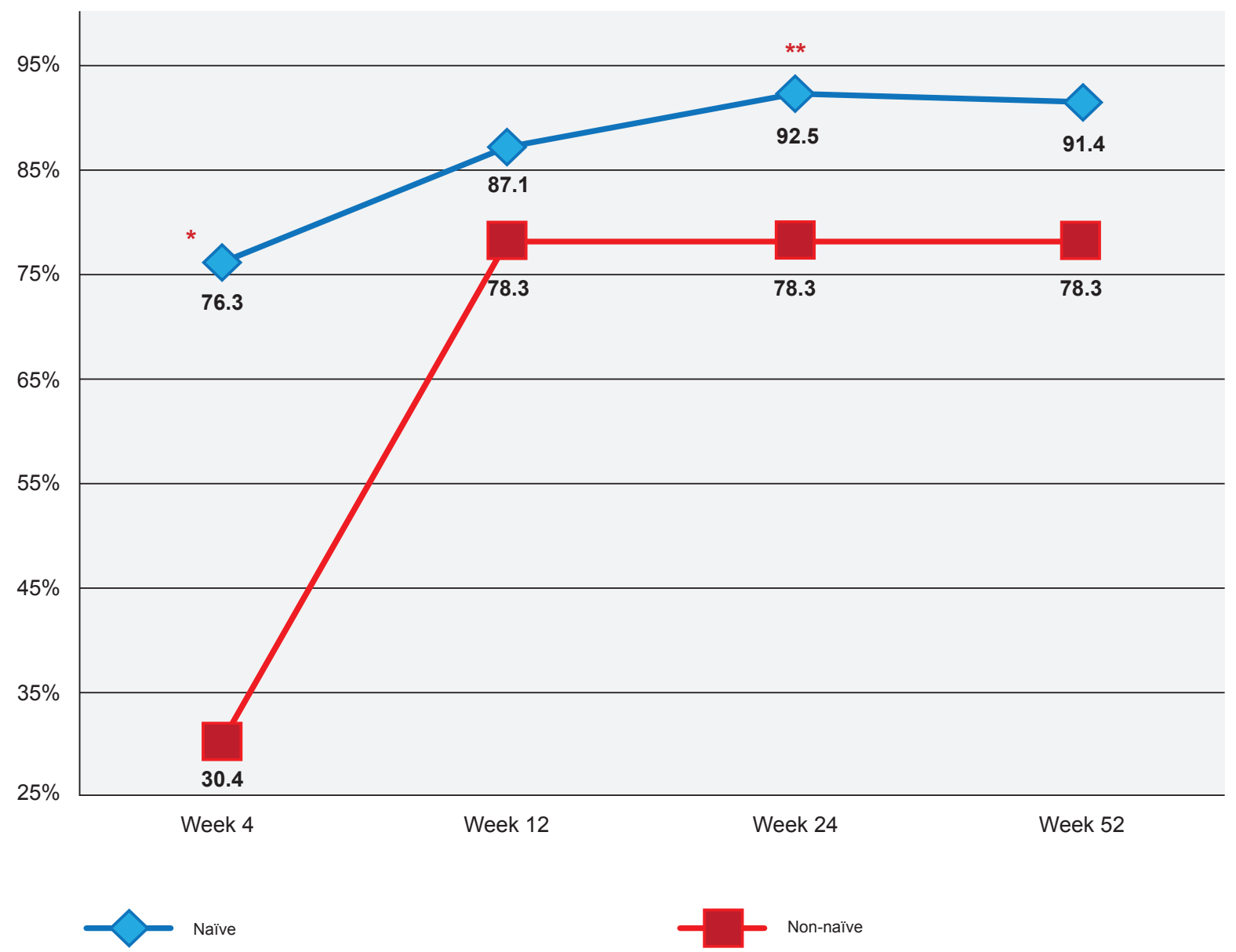

Figure 1 - Clinical response to ustekinumab [PASI75 responders (\%)] in naïve and non-naïve patients. Efficacy data analysed with intention to treat: non-responder imputation (ITT-NRI).

$*: p=0.001 ;{ }^{* *}: p=0.045$ 
garding smoking status, $32.8 \%$ of patients were current smokers, while $21.6 \%$ had smoked in the past.

Pre-treatment infectious screening identified 52 cases of latent tuberculosis and two patients with serologic tests compatible with past hepatitis $\mathrm{B}$ viral infection (HBcAb positive; HBsAg negative; HBV DNA negative).

Regarding previous therapies - phototherapy, cyclosporine, methotrexate and acitretin were previously used in $37.9 \%, 27.6 \%, 23.3 \%$ and $25 \%$ patients, respectively. The majority of our group of patients (93 patients; $80.2 \%$ ), was naïve to biologic treatments. Among the 23 patients (19.8\%) who had prior biologic experience, there was a mean washout period of 5.5 weeks. Infliximab, adalimumab and etanercept were previously used in $21.7 \%, 30.4 \%$ and $47.8 \%$ of patients, respectively. Three patients experienced more than one previous biologic.

\section{Therapeutic response analysis}

The therapeutic response (defined as PASI75 or more) at week 4, 12, 24, 52 was recorded, as was the total treatment duration. Primary endpoint analysis was made at week 12, 24 and 52. Missing data from the main cohort were handled using intention-to-treat non-responder imputation (ITT-NRI) analysis, using SPSS.

Regarding response to treatment, PASI75 response was achieved by $67.2 \%$ (78/116), $85.3 \%$ (99/116), $89.6 \%$ $(104 / 116)$ and $88.7 \%(103 / 116)$ at week 4, 12, 24 and 52, respectively. In our patient cohort, the maximum total group follow-up was week 60 , at which response rate remained sustained (102/116; 87.9\%).

Naïve patients achieved superior clinical response as compared to non-naïve patients, and that was statistically significant at week $24(p=0.045)$ (Fig. 1). This finding goes in line with observations reported by other groups. ${ }^{8,16}$ In fact, the clinical response to a drug switch in patients with biologic experience is generally lower than in naïve patients, not only for ustekinumab, but also for other therapeutic classes. $^{15}$

Regarding treatment interruption, ustekinumab was discontinued in seven patients [3 due to primary failure, 3 due to secondary treatment failure, and one due to adverse event (facial palsy)].

Considering patients that have escaped standard treatment, in 13 dosing intervals were temporarily reduced (8/8 weeks) due to loss of efficacy, and one patient required a dose escalation due to weight gain and worsening of the disease.

Concerning adjuvant therapy, methotrexate was used in one patient at the beginning of treatment (concomitant diagnosis of PsA), and as add-on therapy in eight patients due to loss of clinical response. Five out of eight of these patients later regained PASI75 response. The use of methotrexate is reported to help maintain clinical response, not only due to the drug's adjuvant immunosuppressive action but also owing to a collateral effect of inhibition of production of antidrug antibodies. ${ }^{11}$ No adverse events were reported in this group of patients, but further long-term studies are needed to establish the long-term effects of this immunomodulatory association. Until then, a case-to-case scenario evaluation needs to be assessed for every individual patient.

Considering the treatment response according to the patients' weight (Fig. 2), a tendency to inferior clinical response was observed in patients weighting $90-100 \mathrm{~kg}$. When patients under the standard dose of ustekinumab were analysed, this difference was statistically significant at week $24(p=0.035)$. These observations are in accordance with previous reports, which seem to point to a probable need of up-dosing in these patients, as the proximity to the 'weight-adjustment' threshold makes clinical response to 45 mg of ustekinumab less efficacious. ${ }^{10}$

Seventy-four patients had a follow-up duration of at least 120 weeks. When analysing a cohort subset that
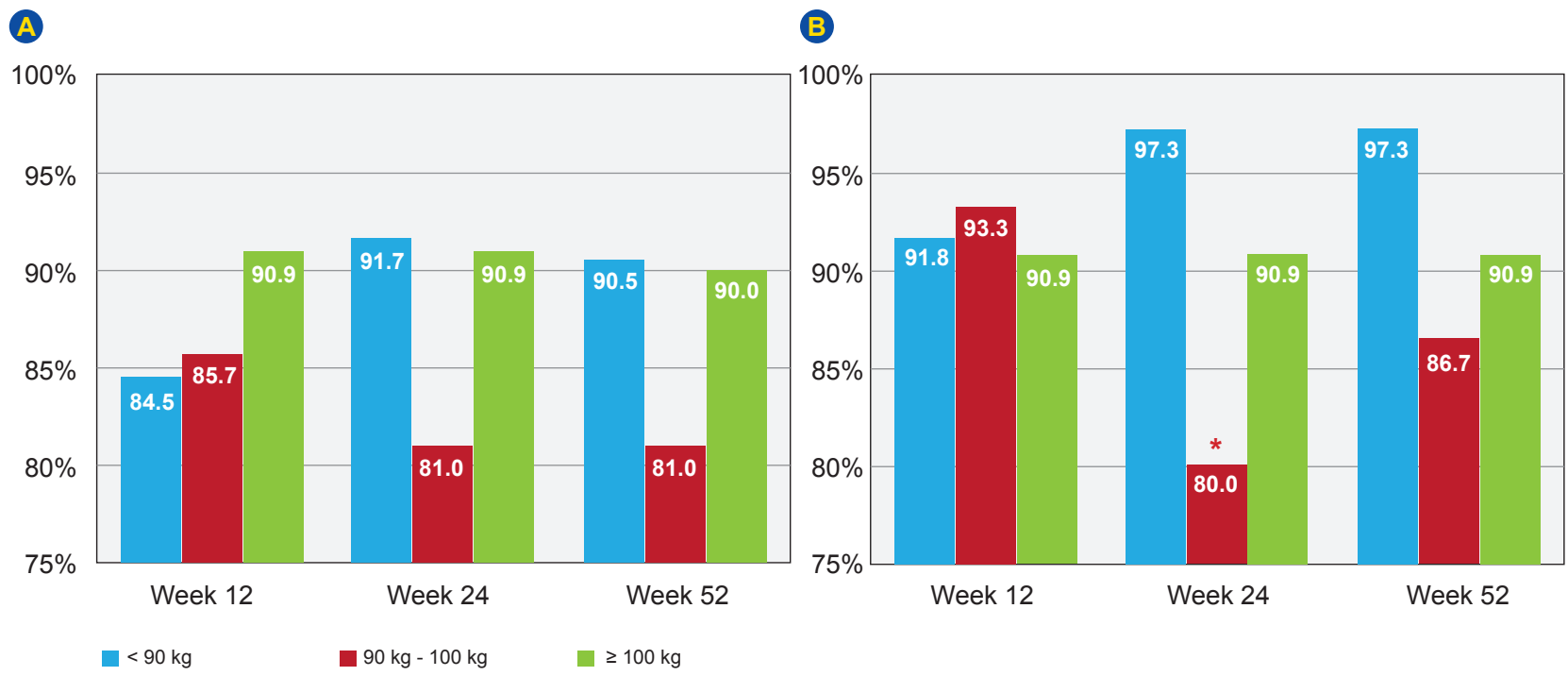

Figure 2 - Number of patients achieving PASI75 response (\%), stratified by weight categories, $<90 \mathrm{~kg}, 90-100 \mathrm{~kg}$ and $\geq 100 \mathrm{~kg}$. (A): total cohort of patients (total n: 116); (B): patients under standard dosage of ustekinumab (total $n: 102$ ).

*: $p=0.035$ 
includes these long-term follow up patients along with patients that discontinued treatment during our study period, the observed PASI75 response was $80.7 \%$ (63/78), $84.6 \%$ (66/78), 87.2\% (68/78), and $94.9 \%(74 / 78)$ at week 12,24 , 52 and 120 . These long-term follow-up PASI75 values underline that the initial response to treatment represents the primary predictor of ultimate therapeutic success in a given patient, and that the continuation of treatment makes failure less probable (excluding factors such as development of side effects or weight increases that lessen drug efficacy).

As far as adverse events, one patient developed facial palsy during treatment (week 180), and even though this event was not proven to be associated to the drug, the possible relation led to ustekinumab suspension. No major adverse cardiovascular events (MACE) were reported during the treatment period. Regarding screening of infectious diseases, adequate prophylaxis was implemented and no reactivations were detected during follow-up.

\section{DISCUSSION AND CONCLUSION}

Our experience with the long-term use of ustekinumab in a heterogeneous group of real-life patients demonstrated an excellent safety profile and absence of major adverse events. Despite a high prevalence of cardiometabolic and infectious comorbidities in our cohort, it is important to note the absence of related SAEs during follow-up.

Upon secondary failure during treatment of moderate to severe psoriasis with biologics, there is uncertainty concerning the decision to either switch to another agent or to intensify the primary biological (by altering drug dose or the frequency of administration). ${ }^{6}$ Decision-making has to take into account not only the expected therapeutic response, but also the economic impact of these options. On the one hand, the cost of introducing a new biological will require taking into consideration not only the new induction phase but also the costs that are inherent to additional medical visits and diagnostic tests..$^{15}$ On the other hand, the cost of the therapy intensification will depend on the amount and duration of the latter. ${ }^{15}$ The suspension and initiation of biologic therapy should be judicious insofar as patients experienced in prior biologics appear to have suboptimal therapeutic response rates, as observed in our patient group.

We report a sustained long-term PASI75 response and treatment persistence in the majority of our group of patients. An inferior therapeutic response was observed in non-naïve patients and patients in the 90 - $100 \mathrm{~kg}$ weight interval, which goes in line with previous reports. This finding seemingly indicates that the proximity to the upper limit of the weight threshold is associated with a significant reduction of therapeutic response rates. The TRANSIT study demonstrated the benefit of dose escalation from 45 to 90 $\mathrm{mg}$ in patients weighting $<100 \mathrm{~kg}$ who did not reach PASI75 at week $28 .{ }^{17}$ Despite the low number of patients in each of the weight categories in our cohort of patients, it seems that the dosage-adjustment threshold may have been set too high. The significance of weight in treatment efficacy emphasizes the importance of regular weight measurements in medical appointments in these patients, as previously suggested. ${ }^{10}$ The usefulness in clinical practice of the awareness and recognition of this group of patients may be noteworthy for implementation of weight reduction plans (dietary change, exercise prescription) along with both temporary dose escalation and interval shortening, prior to taking into consideration drug switching due to treatment failure.

Weight loss is recommended in all psoriatic patients who are overweight or obese. ${ }^{17}$ This measure is essential not only to reduce cardiovascular risk burden, but also to optimize clinical response to several therapies. ${ }^{19}$

In conclusion, ustekinumab is an effective and safe therapeutic agent in patients with moderate to severe psoriasis, and our experience has furthermore shown the ability of recapturing clinical response via temporary dose adjustments as well as a safe drug interaction profile with adjuvant therapy such as methotrexate.

\section{PROTECTION OF HUMANS AND ANIMALS}

The authors declare that the procedures were followed according to the regulations established by the Clinical Research and Ethics Committee and to the Helsinki Declaration of the World Medical Association.

\section{DATA CONFIDENTIALITY}

The authors declare having followed the protocols in use at their working center regarding patients' data publication. Patient consent obtained.

\section{CONFLICTS OF INTEREST}

Tiago Torres has participated as medical consultant/ speaker/advisory board member for Janssen, Pfizer, Abbvie, MSD, Novartis, Lilly, Celgene, Boehringer Ingelheim. The other authors report no conflict of interest.

\section{FUNDING SOURCES:}

This research received no specific grant from any funding agency in the public, commercial, or not-for-profit sectors.

\section{REFERENCES}

1 Leonardi CL, Kimball AB, Papp KA, Yeilding N, Guzzo C, Wang Y, et al. Efficacy and safety of ustekinumab, a human interleukin-12/23 monoclonal antibody, in patients with psoriasis: 76-week results from a randomised, double-blind, placebo-controlled trial (PHOENIX 1). Lancet. 2008;371:1665-74

2 Kimball AB, Papp KA, Wasfi Y, Chan D, Bissonnette R, Sofen H, et al. Long-term efficacy of ustekinumab in patients with moderate-to-severe

psoriasis treated for up to 5 years in the PHOENIX 1 study. J Eur Acad Dermatol Venereol. 2013;27:1535-45.

3 Papp KA, Langley RG, Lebwohl M, Krueger GG, Szapary P, Yeilding $\mathrm{N}$, et al. Efficacy and safety of ustekinumab, a human interleukin-12/23 monoclonal antibody, in patients with psoriasis: 52-week results from a randomised, double-blind, placebo-controlled trial (PHOENIX 2). Lancet. 2008;371:1675-84 
4 Bremmer S, Van Voorhees AS, Hsu S, Korman NJ, Lebwohl MG, Young $\mathrm{M}$, et al. Obesity and psoriasis: from the Medical Board of the National Psoriasis Foundation. J Am Acad Dermatol. 2010;63:1058-69.

5 Zhu Y, Hu C, Lu M, Liao S, Marini JC, Yohrling J, et al. Population pharmacokinetic modeling of ustekinumab, a human monoclonal antibody targeting IL-12/23p40, in patients with moderate to severe plaque psoriasis. J Clin Pharmacol. 2009;49:162-75.

6 Langley RG, Lebwohl M, Krueger GG, Szapary PO, Wasfi Y, Chan D, et al. Long-term efficacy and safety of ustekinumab, with and without dosing adjustment, in patients with moderate-to-severe psoriasis: results from the PHOENIX 2 study through 5 years of follow-up. $\mathrm{Br} \mathrm{J}$ Dermatol. 2015;172:1371-83.

7 Vergou T, Moustou AE, Antoniou C. Five-year experience with ustekinumab for psoriasis: real-life data of a single centre. J Eur Acad Dermatol Venereol. 2017;31:e40-1.

8 Ruiz Salas V, Puig L, Alomar A. Ustekinumab in clinical practice: response depends on dose and previous treatment. J Eur Acad Dermatol Venereol. 2012;26:508-13.

9 Pinheiro RR, Duarte B, Ferreira A, Cabete J. Ustekinumab in patients previously treated with TNFalpha inhibitors: a real-life study. Eur J Dermatol. 2018;28:89-91.

10 Laws PM, Downs AM, Parslew R, Dever B, Smith CH, Barker JN, et al. Practical experience of ustekinumab in the treatment of psoriasis: experience from a multicentre, retrospective case cohort study across the U.K. and Ireland. Br J Dermatol. 2012;166:189-95.

11 Wilder EG, Patel M, Hebeler K, Menter A. Ustekinumab treatment for psoriasis in 119 patients maintained on therapy for a minimum of one year: a review. J Drugs Dermatol. 2014;13:905-10.

12 Molina-Leyva A, Husein-Elahmed H, Naranjo-Sintes R, Ruiz-Carrascosa
JC. Safety and effectiveness of ustekinumab for treatment of moderate to severe psoriasis: a prospective study in a clinical setting. J Drugs Dermatol. 2014;13:971-4.

13 Ormerod $A D$. Five-year follow-up of ustekinumab efficacy: the influence of dose modification. Br J Dermatol. 2015;172:1193-4

14 Mrowietz U, de Jong EM, Kragballe K, Langley R, Nast A, Puig L, et al. A consensus report on appropriate treatment optimization and transitioning in the management of moderate-to-severe plaque psoriasis. J Eur Acad Dermatol Venereol. 2014;28:438-53.

15 Puig L. Treatment of moderate to severe plaque psoriasis with biologics: analysis of the additional cost of temporary dose escalation vs switch to another biologic after failure of maintenance therapy. Actas Dermosifiliogr. 2014;105:401-12.

16 Puig L, Ruiz-Salas V. Long-term efficacy, safety and drug survival of ustekinumab in a Spanish cohort of patients with moderate to severe plaque psoriasis. Dermatology. 2015;230:46-54

17 Reich K, Puig L, Paul C, Kragballe K, Luger T, Lambert J, et al. Oneyear safety and efficacy of ustekinumab and results of dose adjustment after switching from inadequate methotrexate treatment: the TRANSIT randomized trial in moderate-to-severe plaque psoriasis. $\mathrm{Br} \mathrm{J}$ Dermatol. 2014;170:435-44.

18 Kimball AB, Gladman D, Gelfand JM, Gordon K, Horn EJ, Korman NJ, et al. National Psoriasis Foundation clinical consensus on psoriasis comorbidities and recommendations for screening. J Am Acad Dermatol. 2008;58:1031-42.

19 Puig L. Obesity and psoriasis: body weight and body mass index influence the response to biological treatment. J Eur Acad Dermatol Venereol. 2011;25:1007-11. 